\title{
Accident proneness of bus drivers; controlling for exposure
}

\author{
by Dorn L, af Wåhlberg AE
}

\begin{abstract}
It is argued that the reason for previous evidence apparently not supporting the accident proneness hypothesis was due to erroneous methodology and interpretations of results. When restriction of variance is controlled for, traffic accident records of different time periods actually show an impressive stability over time. However, it could be argued that stability is caused by stable differencearbouss in exposure.

Correlations of accident records between time periods were analysed comparing full time and parttime bus drivers. For drivers who worked full time, the amount of exposure was held semi-constant while part-time drivers could be expected to work differing hours. If differential exposure causes stability in crash record, then part-time drivers should yield stronger correlations between time periods for crashes compared with full-time drivers.

Between time periods accident correlations for part-time drivers were weaker than the corresponding ones for full time drivers. Correlations increased with increasing variance in the data. Results for all crashes fit in well with other meta-data, while culpable crashes did not, probably due to faulty coding. The current results support the notion of the tendency to be involved in traffic accidents as a stable trait within individuals which is not caused by stable differences in exposure.
\end{abstract}

Key words: accident proneness; bus driver; accident record; crash; reliability 
Relevance to human factors/ergonomics theory

There exist no theory which explain the results reported in this paper, apart from accident proneness. That theory, however, is far from fully developed, and the inherent possibilities of a theory which assumes stability of accident-causing behaviour over time are largely unexplored.

\section{Introduction}

\subsection{The concept of accident proneness}

Accident proneness is the oldest hypothesis about individual differences within safety research (see Greenwood \& Woods, 1919; Greenwood \& Yule, 1920; Farmer \& Chambers, 1926). It is also one of the most researched and contested concepts. After the initial wave of positive reactions and results in the early 20th century (e.g. Newbold, 1927), the number of critics increased (see the reviews by Froggatt \& Smiley, 1964; Sass \& Crook, 1981; Porter, 1988), and by the eighties, few researchers still defended, used or talked about accident proneness in research (for some exceptions, see Baker, Li, Lamb \& Warner, 1995; Engel, 1991; Miyazaki, Chou \& Maryama, 1994; Visser, Pijl, Stolk, Neeleman \& Rosmalen, 2007)1․ This was despite the fact that most studies on the prediction of individual differences in accident record uses the (unstated) assumption of stability of crash-causing behaviour over time periods of some years (af Wåhlberg, 2009). If such behaviour was unstable, differences in crash tendency could not be predicted at all from measures of individuals made at one point in time.

But what is accident proneness, and why was it so heavily criticised? In essence, accident proneness was the notion that there are individual differences in the tendency to cause accidents, and that these tendencies are fairly stable over time and across environments, i.e. it is an innate characteristic which is not changed by, for example, accident involvement (e.g. Crawford, 1971; Bernacki, 1976; some alternative models assumed that an accident influenced the probability of another one occurring, either positively or negatively; Arbous \& Kerrich, 1951).

Three main methods for investigating whether accident proneness actually exist have been used; 1) comparing accident distributions to assumed chance distributions, 2) predicting accident involvement from tests, and 3) estimating the stability of accident record over time (which can be seen as a special case of 2, where the test is replaced by previous accidents, or citations).

\subsection{Literature review}

Most accident proneness research seems to have been concerned with testing whether accident proneness exists by comparing an actual accident distribution with a random distribution. A non-random distribution was thought to indicate that some people had more accidents than could be expected by chance. Unfortunately, statisticians could not agree how a random distribution should be constructed or what it meant (e.g. Maritz, 1950; Arbous \& Kerrich, 1951; Blum \& Mintz, 1951; Webb \& Jones, 1953), and the method was therefore discontinued, until it was revived by Visser, Pijl, Stolk, Neeleman and Rosmalen (2007). Also, given the idea of individual differences in stable accident-causing behaviour, many researchers tried to construct psychological tests to predict accident involvement, i.e. they tried to measure accident proneness (e.g. Kunce, 1967). This included some early driving simulators, but most tests were psychophysical, concerning, for example reaction times (e.g.

\footnotetext{
${ }^{1}$ Furthermore, the stability of accident record over time (a central tenet of accident proneness) has been investigated without this term being used (e.g. Cantor, Corsi, Grimm \& Özpolat, 2010; Lueck \& Murray, 2011)
} 
Slocombe \& Brakeman, 1930). When such tests had very little success in predicting accident involvement, some researchers drew the conclusion that the idea of accident proneness was erroneous, not that the tests were faulty (e.g. Crawford, 1971).

Research to predict accident involvement from previous accidents was fairly uncommon amongst safety researchers in general, but somewhat more popular within traffic safety (see the reviews and analyses in af Wåhlberg, 2009). After a few decades, most researchers appeared to conclude that the effect sizes reported were too small to constitute evidence of stability of accident record over time (e.g. Haight, 2001). Thus, no conclusive evidence was published in support of accident proneness, and the use of this concept started to decline. We have previously argued that the apparent lack of supporting evidence for accident proneness is misleading (af Wåhlberg, 2009; af Wåhlberg \& Dorn, 2009; 2019). Firstly, there is little agreement among statisticians about what a distribution of random events look like (e.g. Arbous \& Kerrich, 1951; Smeed, 1960), and this kind of research is therefore not relevant. Secondly, when tests for accident proneness yield small or non-existing predictive power, this can always be due to the validity of the tests, and therefore does not tell us anything about the stability of accident-causing behaviour. Thirdly, low coefficients when predicting individual differences in accident record have been shown to be due to restriction of variance in the crash variable (af Wåhlberg, 2009; af Wåhlberg, Barraclough \& Freeman, 2015; 2016; Barraclough, af Wåhlberg, Freeman, Watson \& Watson, 2016). As the variance in the accident variable increases, so do the predictive coefficients. This effect is especially strong for prediction of accidents from previous accidents, as about 80 percent of the variance between samples is due to restriction of variance (af Wåhlberg, 2009).

Furthermore, none of the research avenues described above took into account culpability for accidents (although it was sometimes discussed, see Crawford, 1960), which presumably inserted a fair amount of error variance in all calculations. This is especially the case for road traffic accidents, as these often have two or more parties, one of which may be an innocent victim (Dorn \& af Wåhlberg, 2018; af Wåhlberg, 2009; af Wåhlberg \& Dorn, 2007). It should be remembered that the accident proneness idea is about causing mishaps, not about being in the wrong place at the wrong time.

One final problem, which is part of the accident proneness research, is whether the correlations between accidents in different time periods are actually caused by stable differences in exposure. It has been found that people who drive more tend to have more crashes (af Wåhlberg, 2009; 2011). If this tendency is stable over time, it could lead to positive in-between time periods correlations for crashes irrespective of the behaviour of the driver. Such a confounding effect of exposure has previously been found to explain a large part of the correlation between the Driver Behaviour Questionnaire violation scale and crashes (af Wåhlberg, Barraclough \& Freeman, 2015), and is therefore not to be discounted as an explanation.

In the published literature, it is difficult to ascertain the exact effect of differing amounts of exposure on the stability of accident record. For non-professional drivers, it can be assumed that mileage does indeed differ substantially between drivers. If this kind of data has not been gathered, exposure cannot be controlled for. Furthermore, sometimes mileage data has been gathered, but the reported statistics do not specifically include this effect. Papers with either of these characteristics include Burg (1970), Daigneault, Joly and Frigon (2002), French, West, Elander and Wilding (1993), Gebers (2003), Harrington (1972), Hauer, Persaud, Smiley and Duncan (1991), Miller and Schuster (1983), Peck and Kuan (1983), Peck, McBride and Coppin (1971) and West, Elander and French (1992). No paper has been found which controls for mileage amongst non-professional drivers.

For professional drivers, it could be assumed that most drivers work full time, and that the amount of exposure is therefore fairly uniform (apart from sickness leave and extra time 
worked). However, some studies on professional drivers have not mentioned this aspect at all (e.g. Bach, Bickel \& Biehl, 1975; McKenna, Duncan \& Brown, 1986) while others have only discussed the circumstances of exposure in general in such a way that it can be concluded that all drivers worked full time (Cresswell \& Froggatt, 1963; Farmer \& Chambers, 1939;

Häkkinen, 1958; 1979; Moffie \& Alexander, 1953). Although mileage has been controlled for in some of these studies, it is not possible to ascertain whether coefficients would have been larger if this had not been the case. As no previous study has specifically tested the effect of differential exposure on the stability of accident record over time, with the exception of af Wåhlberg and Dorn (2019), this question would seem to remain largely unexplored.

\subsection{Aims of the study}

The question can then be posed how the effects of amount of exposure can be tested? It is possible to undertake this in three different ways. First, if the mileage or number of hours driven is known, correlations between crashes in different time periods can be calculated with and without this control. Only af Wåhlberg and Dorn (2019) have reported such figures. Second, for professional drivers, correlations for full time drivers can be compared to those for part-time drivers. If differential amount of exposure is indeed causing an increased stability in crash record, the latter should yield higher values. This type of analysis has never been published before. However, to make the comparison fair, the difference in means of crashes between groups must be controlled for, as part-time drivers can be expected to have a lower mean, which deflates the stability coefficient.

Third, between time periods correlations can be compared to previously published results in a type of meta-analysis, where the correlations are plotted against their means of crashes (af Wåhlberg, 2009). Samples which deviate from the pattern of a very strong association between the correlation and the mean of crashes must have some other characteristic which causes this. If both full-time and part-time driver samples fit the pattern, it can be concluded that differential exposure does not seem to be influencing the correlations. This method cannot be said to be fully reliable for the present type of data, given the uncertainty of exposure status for professional drivers in most of the previous studies. However, if both types of samples fit the previously found pattern, it can at least be said that the effect of exposure must be very small, as most of the variance is explained by the means of crashes. Based upon the evidence presented in this introduction, we therefore state the following hypotheses;

1) Crash involvement in different time periods correlate positively for drivers, and these correlations increase as the crash means of the total periods increase (i.e. longer periods are used, or samples with higher risk).

2) At fault crashes correlate more strongly between time periods than do all crashes, when the crash mean is controlled for and culpability is correctly coded.

3) The between time periods correlations of crashes are not influenced to any large degree by exposure, as evidenced by similar effect sizes for full time and part-time drivers when differences in crash means have been controlled for.

To investigate these hypotheses, we used a set of bus driver crash data. Hypothesis 1 was investigated by correlating the number of crashes per driver in three different (consecutive) time periods. Hypothesis 2 was tested by comparing the correlations for at fault crashes (which is a sub-set of all crashes) with the correlations for all crashes. Hypothesis 3 was tested within the present dataset by comparing full and part time drivers, and by comparing the 
results for these samples with meta-analytic data from af Wåhlberg (2009), to see whether the results of the present study fit the previously reported pattern.

\section{Method}

\subsection{Setting}

The study used crash data supplied by a British bus company for an (unpublished) evaluation study. At the time when the data was gathered, the bus company was operating on over 700 different routes in Greater London with over 6,800 scheduled buses.

Buses in London are usually double decker measuring between 9.5 metres and 11.1 metres long, weighing between 7 ton and 12 ton depending on number of passengers. These buses operate on the most congested roads in the UK, amongst pedestrians and other vulnerable road users.

\subsection{Data}

Data for the time period 2006-2008 was available, including number of at fault and no fault crashes $^{2}$ (defined as collisions with other objects, but excluding falls and other injuries inside the bus). The data was arranged with driver as the unit of analysis and crashes per year as variables. The drivers had been judged for culpability by company officials, and crash variables were therefore constructed as all crashes and at fault, a sub-set of all crashes. Date of birth, current full time or part time employment, and date of employment commenced, for each driver, were included in the database. These data were linked to the crashes by employment numbers. Two samples of drivers were extracted. In sample 1, only full time drivers were included, to hold amount of risk exposure constant. Sample 2 consisted of parttime drivers, where it was assumed that risk exposure was unequal between drivers. Only drivers who worked during the full study period of 2006-2008 were included in the samples. As can be seen in Tables 1-2, the crash variables were somewhat skewed, with many drivers having no crashes within this time period. As could be expected from their lower exposure, the part time drivers had lower accident means per year.

\subsection{Analyses}

Detailed descriptive statistics were calculated (see Tables 1-2). This type of information has been found to be very important when studies are meta-analysed (af Wåhlberg, 2009), as they explain large parts of the differences in effect sizes between studies (af Wåhlberg, Barraclough \& Freeman, 2016; 2016). In studies on individual differences in accident record, the average number of crashes tend to be strongly related to the standard deviation, and both of these has an influence on the effect size obtained; higher means and standard deviations yield larger effects. In this study, the skewness of the variables was also computed, as this measure of the uneven distribution of values in the sample could also influence the effect size values.

Pearson correlations were used for all zero-order analyses to investigate the association of crashes in between time periods. This statistic can be converted into a number of other effect sizes (Field \& Gillett, 2010), and is often used in studies on individual differences in accident record (af Wåhlberg, 2009; af Wåhlberg, Barraclough \& Freeman, 2016). Therefore, the

\footnotetext{
${ }^{2}$ The terminology used here is similar to that of our definition of behavioural culpability (af Wåhlberg \& Dorn, 2007), but it is probably used to determine legal responsibility by the present company.
} 
present results can be compared to other findings, i.e. meta-analysed along with previous results in this field (af Wåhlberg, 2009).

The type of meta-analysis applied in the present study can be viewed as a kind of moderator analysis. It has been found that the correlation between crashes in different time periods is heavily dependent upon the variance in the variables (af Wåhlberg, 2009), which can be estimated from the mean of crashes. Therefore, longer time periods and samples with higher risk will yield larger coefficients. As the current samples did not yield enough values to establish exactly how the coefficients increase with the variance (as estimated from the mean), previously published data from af Wåhlberg (2009) was used for this purpose. When a formula has been established for the increase in coefficients, this can be applied to hold variance constant in the current data, and make it possible to compare full time and part time drivers. This can be done by calculating the expected coefficients for their level of variance and the deviance of the actual values from these. However, it can also be accomplished by simply looking at the scatter plot of the association between correlations and means. If the part time drivers' values conform to the general pattern, their unequal exposure is not strengthening the correlations.

Table 1 Descriptive statistics for sample 1, with accidents for the period 2006-2008. Only full-time drivers who worked during the whole period were included. $\mathrm{N}=2277$.

\begin{tabular}{|l|l|l|l|l|}
\hline Variable & Mean & Standard deviation & Min-max & Skewness \\
\hline All accidents 2006 & 1.134 & 1.316 & $0-11$ & 1.68 \\
\hline All accidents 2007 & 1.003 & 1.176 & $0-8$ & 1.57 \\
\hline All accidents 2008 & 0.780 & 0.963 & $0-7$ & 1.48 \\
\hline At fault accidents 2006 & 0.525 & 0.805 & $0-6$ & 1.84 \\
\hline At fault accidents 2007 & 0.427 & 0.697 & $0-5$ & 1.77 \\
\hline At fault accidents 2008 & 0.339 & 0.624 & $0-4$ & 2.05 \\
\hline Age 2007-06-30 (years) & 44.3 & 9.7 & $21.6-69.5$ & 0.17 \\
\hline Experience 2007-06-30 (years) & 6.8 & 5.6 & $1.5-43.3$ & 2.75 \\
\hline
\end{tabular}

Table 2 Descriptive statistics for sample 2, with accidents for the period 2006-2008. Only part-time drivers who worked during the whole period were included. $\mathrm{N}=93$.

\begin{tabular}{|l|l|l|l|l|}
\hline Variable & Mean & Standard deviation & Min-max & Skewness \\
\hline All accidents 2006 & 0.753 & 0.996 & $0-4$ & 1.26 \\
\hline All accidents 2007 & 0.796 & 0.927 & $0-4$ & 1.09 \\
\hline All accidents 2008 & 0.559 & 0.926 & $0-4$ & 1.84 \\
\hline At fault accidents 2006 & 0.376 & 0.678 & $0-2$ & 1.52 \\
\hline At fault accidents 2007 & 0.430 & 0.649 & $0-3$ & 1.48 \\
\hline At fault accidents 2008 & 0.247 & 0.503 & $0-2$ & 1.94 \\
\hline Age 2007-06-30 (years) & 45.4 & 12.0 & $24.8-68.2$ & 0.41 \\
\hline Experience 2007-06-30 (years) & 7.8 & 7.2 & $1.6-41.0$ & 2.78 \\
\hline
\end{tabular}

\section{Results}

In Tables 1-2 the descriptive statistics for the samples are displayed. A downward trend for crashes over time can be seen, which may be explained with reference to a general reduction in accident rate in the UK during this period; a casualty reduction of 11 percent between 2006 and 2008 has been reported (Department for Transport, 2008; 2009).

Next, the associations between number of crashes in different single years were investigated, for at fault and all crashes. As can be seen in Tables 3-4, these correlations were rather strong for this kind of study and time periods of single years (af Wåhlberg, 2009). This finding was expected, due to the high crash means (i.e. high variation) in the samples. Also, the correlations were much stronger when two years were summed and correlated with the third 
year (Tables 5-6), i.e. correlations increase with the means of the crash variables (hypothesis 1).

Table 3 The correlations between number of accidents per driver (unit of analysis) in different (single) years in sample 1. All accidents in the lower left corner, at fault accidents only in the upper right. $\mathrm{N}=2277$.

\begin{tabular}{|l|l|l|l|}
\hline Variable & 2006 & 2007 & 2008 \\
\hline 2006 & - & $.184 * * *$ & $.157 * * *$ \\
\hline 2007 & $.317 * * *$ & - & $.144 * * *$ \\
\hline 2008 & $.256 * * *$ & $.239 * * *$ & - \\
\hline
\end{tabular}

$* * * \mathrm{p}<.001$

Table 4 The correlations between number of accidents per driver (unit of analysis) in different (single) years in sample 2. All accidents in the lower left corner, at fault accidents only in the upper right. $\mathrm{N}=93$.

\begin{tabular}{|l|l|l|l|}
\hline Variable & 2006 & 2007 & 2008 \\
\hline 2006 & - & .024 & .110 \\
\hline 2007 & $.215^{*}$ & - & .170 \\
\hline 2008 & $.258^{*}$ & $.324 * *$ & - \\
\hline
\end{tabular}

$* \mathrm{p}<.05, * * \mathrm{p}<.01$

Table 5 The correlations between number of accidents per driver (unit of analysis) in different time periods (combinations of two versus one year) for sample 1. Values for all/at fault accidents) $\mathrm{N}=2277$.

\begin{tabular}{|l|l|l|l|}
\hline Variable & $2006-2007$ & $2007-2008$ & $2006 / 2008$ \\
\hline 2006 & - & $.367 * * * / 226 * * *$ & - \\
\hline 2007 & - & - & $.275 * * * / .232 * * *$ \\
\hline 2008 & $.277 * * * / .173 * * *$ & - & - \\
\hline
\end{tabular}

Table 6 The correlations between number of accidents per driver (unit of analysis) in different time periods (combinations of two versus one year) for sample 2. Values for all/at fault accidents) $\mathrm{N}=93$.

\begin{tabular}{|l|l|l|l|}
\hline Variable & $2006-2007$ & $2007-2008$ & $2006 / 2008$ \\
\hline 2006 & - & $.290 * * * / 080$ & - \\
\hline 2007 & - & - & $.338 * * / .116$ \\
\hline 2008 & $.372 * * * / .195$ & - & - \\
\hline$* * * \mathrm{p}<.001$ & \multicolumn{3}{l}{} \\
\hline
\end{tabular}




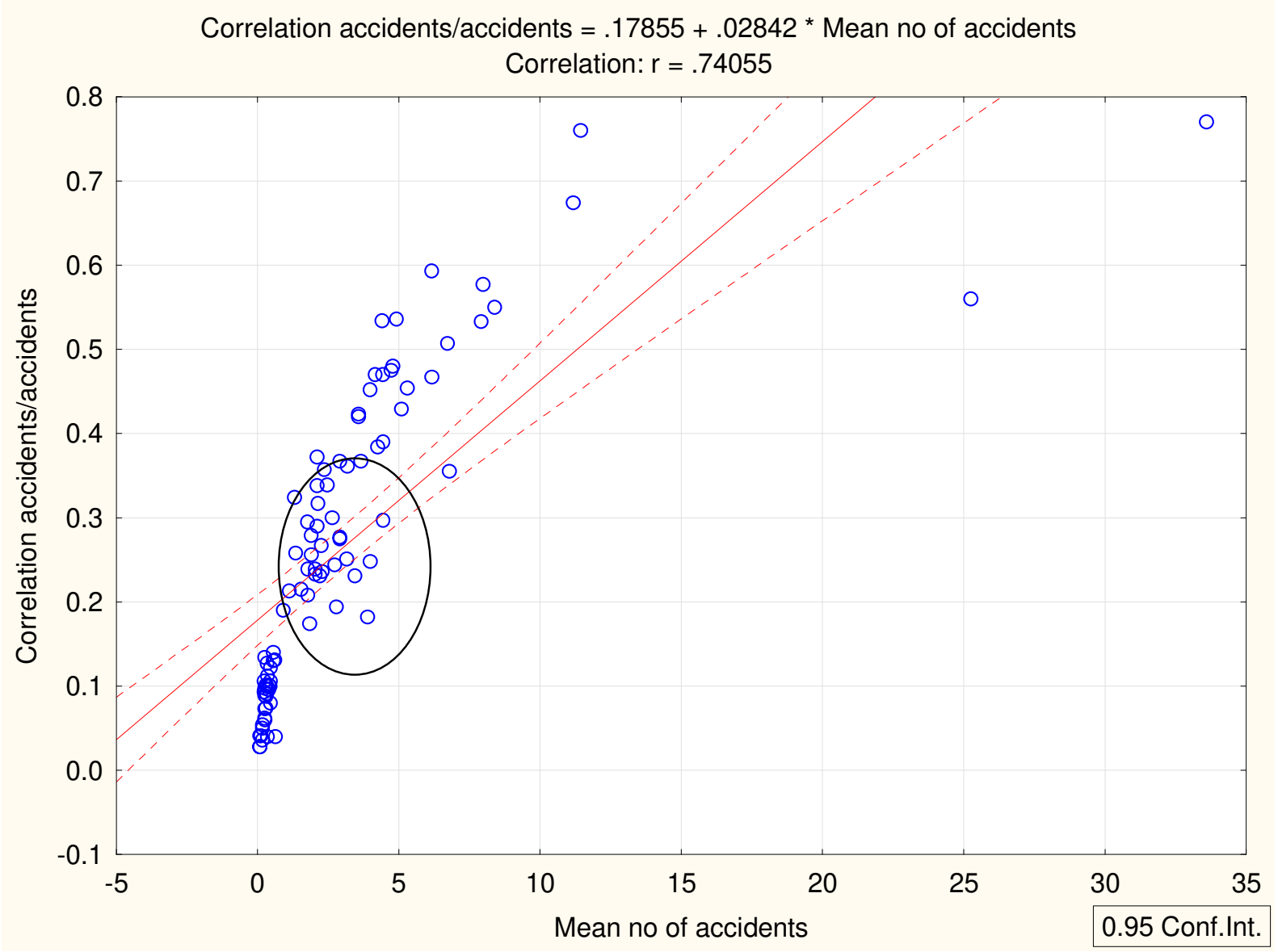

Figure 1 The (meta-analytic) association between correlations between crashes in different time periods and the mean number of crashes for the whole time period in the sample, for all accidents. Meta-data from af Wåhlberg (2009), with the present results added, $k=92$. Values were not independent (groups of correlations were taken from the studies), and were taken from both non-professional and professional driver samples. The data points from the present study are all within the drawn ellipse.

Thereafter, these correlations were entered into the meta-analytic data for accident proneness from af Wåhlberg (2009), i.e. correlations for crashes in different time periods from various studies. The mean number of crashes for the total time period was also entered. Figures 1-2 show scatter plots for the association between time periods correlations and the mean number of crashes for the total time period. The data points from the present study were marked and fit well with other data. 


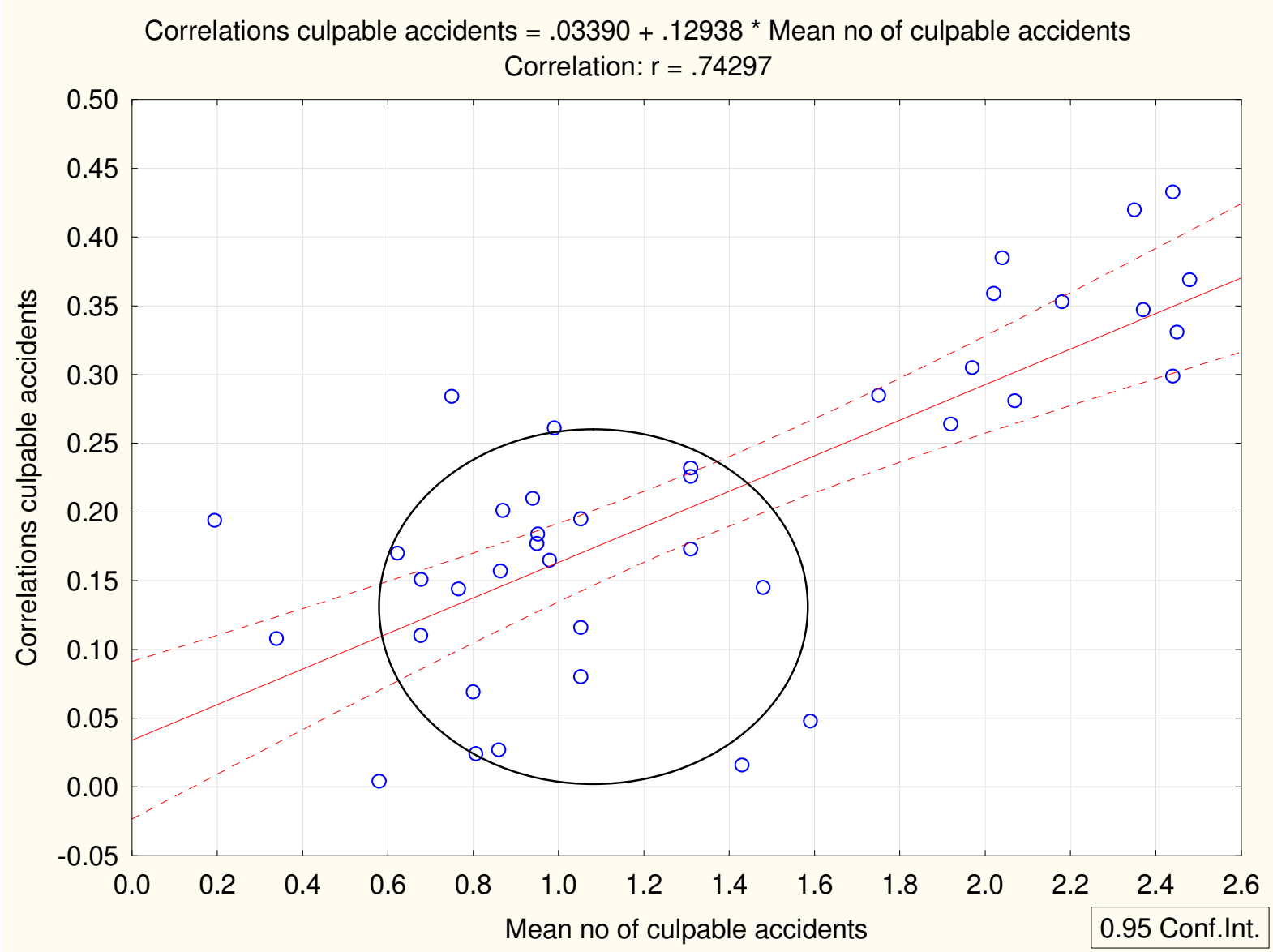

Figure 2 The association between correlations between culpable crashes in different time periods and the mean number of culpable crashes for the whole time period. Meta-data from af Wåhlberg (2009), with the present results added, $\mathrm{k}=40$. Values were not independent (groups of correlations were taken from the studies), and were taken from both non-professional and professional driver samples. The data points from the present study are all within the drawn ellipse.

To ascertain whether the difference in size of correlations for full time and part time drivers were due to different variances, the regression formula for the meta-analytic association between correlations and crash means for professional drivers (a sub-set of the data shown in Figures 1-2) was used to calculate expected correlations from the means for the two samples. Thereafter, the deviation of the actual values from the expected ones could be calculated. Under the assumption that most previous studies have indeed used full time drivers, the part time sample should deviate more, in a positive direction, than the full time sample.

The regression formula for all crashes was $0.162+0.05058 *$ mean of crashes, and for culpable ones; $0.168+0.1393 *$ mean of crashes. Calculated from these values, it was found that there was indeed a positive deviance for the part time drivers for all crashes, which was larger than for the full time drivers. For culpable crashes, however, the result was reversed, with a larger negative deviance for the part time drivers. There was thus no evidence of any increase in effect sizes for the part time sample (hypothesis 3 ).

Similarly, calculated on both samples, culpable crashes had some 50 percent smaller correlations than expected, while all crashes had ten percent higher values than expected. The current data can therefore be seen to deviate from the pattern of previous data concerning the distinction between all crashes and culpable ones and does not conform to the predicted effect (hypothesis 2). 


\section{Discussion}

\subsection{Results}

As can be seen from the results, accident records for bus drivers are indeed stable over time. The degree of stability fits well with previously published data, with the mean of accidents in the sample as a very strong determinant (moderator) of the effect sizes found. Evidence of a stronger stability for at fault crashes was not found, however.

If stable differences in amount of driving cause part of the stability of crash record between time periods, full time drivers should yield weaker between-periods correlations than part time drivers. Comparing results for these groups showed that this was not the case. It could then be argued that part time drivers were working differing hours in different years and that the comparison does not yield any evidence concerning the causes of stability. However, if part time drivers do not work a stable set of hours between years, which differs between drivers, it would be at odds to claim that the full time drivers could differ in this respect. What can be concluded from these calculations is therefore that amount of exposure does not seem to influence the correlations in this dataset.

\subsection{Limitations}

As usual, there are many methodological problems inherent in the present study, which could be forwarded as explaining the results. In the current data, the main problem is the use of company data gathered for purposes other than research. Errors and biases of various types could therefore have contaminated the data.

It is possible that some drivers had been driving more dangerous routes than others. This kind of effect has been investigated by Häkkinen (1979) and found to be negligible for stability (although the risks differed between routes, duty rotation cancelled this effect). Cresswell and Froggatt (1963), on the other hand, did find significant differences between groups of drivers, but those were for larger geographical areas and types of buses/services, and are thus not applicable for the present data.

The basis of the methodology is really the assumptions concerning full time and part time drivers work patterns, for which there was no detailed data available. It is conceivable that working hours were not distributed in the way required for the computations to be valid. More specifically, part time drivers could have been working on very uneven schedules, thus creating differences in exposure which were not stable over time. There is no possibility of ascertaining to which degree this could have been the case.

Sick leave data was not available. It is therefore possible that some drivers with poor health were more often on leave and therefore were less exposed to risk, in a manner that would be stable over time. However, this should at least have the same kind of effect for full time and part time drivers, unless some sort of assumption about differences in health between these categories is made.

Hypothesis 2, concerning the effect of culpability on stability of accident record was not upheld in the present data. However, this could be expected, as previous investigations have indicated that in the present dataset, culpability has not been correctly assigned (Dorn \& af Wåhlberg, 2018). Whether the size of this error can explain the size of the deviance would be possible to calculate, but was beyond the aims of the current study.

\subsection{Conclusions}

The novelty in the present study lies in the test of effects of differential exposure on the stability of crash record over time by comparing samples with different exposure patterns. 
Only af Wåhlberg and Dorn (2019) has reported accident proneness coefficients controlled for exposure, but used hours of driving instead of type of employment.

What can the concept of accident proneness be useful for? For one thing, it stresses the importance of inherited characteristics and/or habitual behaviour in traffic rather than the effects of the environment. This gives a very different perspective on accident involvement, and possibilities for future research. For example, research into how strongly accident record is inherited in families is rare (for an exception, see Bianchi \& Summala, 2004).

The accident proneness concept would also predict that driver behaviour is rather difficult to change in the long term, as evidenced by the failure of all types of driver education and training (Lonero, 2008; Ker et al., 2005; Masten \& Peck, 2004; Mayhew \& Simpson, 2002; Peck, 2011; Roberts, Kwan \& Cochrane Injuries Group Driver Education Reviewers, 2008; Strathman, Kimpel \& Leistner, 2007; af Wåhlberg, 2007a; but see also af Wåhlberg, 2018). This consequence of accident proneness would seem to indicate the importance of individual differences in traffic safety, and the need to develop better methods for identifying them before hiring drivers. Similarly, if individual differences in accident proneness in drivers who have been hired can be detected before crashes start to happen, drivers high on this trait could be targeted with better interventions using behavioural change techniques, or removed from this type of job.

However, the accident proneness concept is difficult to use when it comes to removing dangerous drivers from the population, if crash data is the only information available, as shown by Arbous and Kerrich (1951; Bernacki, 1976). The stability of crash record is only apparent when the time periods studied are rather long. It will take years before even a rather extreme professional driver has accumulated so many crashes as to make it very certain that this person should not be driving, and for non-professional drivers it could be decades. Better methods for identifying accident proneness are therefore the preferable solution.

But how should accident proneness be measured? In the present paper, only a secondary effect of this apparent trait has been studied, as in the main, accidents are the outcome of behaviour. It is this behaviour which accident proneness predicts to be stable over time. However, research into this kind of question is very rare within traffic safety (for exceptions, see Whitlock, Clouse \& Spencer, 1963; af Wåhlberg, 2004; 2007b), where participants are seldom measured more than once. This lack of knowledge of about the stability of various measurements thought to be related to crash involvement probably explain the mostly very small coefficients found in such studies (e.g. Vaa, 2003; af Wåhlberg, Barraclough \& Freeman, 2015; 2016). If test-retest reliability of measurements could be improved upon, for example by averaging them over several occasions, this would improve their predictive power (Rushton, Brainerd \& Pressley, 1983; af Wåhlberg, 2009). It can therefore be concluded that research into individual differences in crash tendency need to take the stability issue into account more often, so that more efficient tests of accident proneness can be developed.

\section{Acknowledgement}

The data used in this paper was generously made available to us by a major British bus company. Several anonymous reviewers suggested various improvements, which is gratefully acknowledged. 


\section{References}

Arbous, A. G., \& Kerrich, J. E. (1951). Accident statistics and the concept of accident proneness. Biometrics, 7, 340-432.

Baker, S. P., Li, G., Lamb, M. W., \& Warner, M. (1995). Pilots involved in multiple crashes: "accident proneness" revisited. Aviation, Space and Environmental Medicine, 66, 6-10.

Barraclough, P., af Wåhlberg, A. E., Freeman, J., Watson, B., \& Watson, A. (2016).

Predicting crashes using traffic offences. A Meta-Analysis that examines potential bias between self-report and archival data. PLOS ONE.

http://dx.doi.org/10.1371/journal.pone.0153390

Bernacki, E. J. (1976). Accident proneness or accident liability: Which model for industry? Connecticut Medicine, 40, 535-538.

Bianchi, A., \& Summala, H. (2004). The "genetics" of driving behavior: parents' driving style predicts their children's driving style. Accident Analysis and Prevention, 36, 655-659.

Blum, M. L., \& Mintz, A. (1951). Correlation versus curve fitting in research on accident proneness: Reply to Maritz. Psychological Bulletin, 48, 413-418.

Burg, A. (1970). The stability of driving record over time. Accident Analysis and Prevention, 2, 57-65.

Cantor, D. E., Corsi, T. M., Grimm, C. M., \& Özpolat, K. (2010). A driver focused truck crash prediction model. Transportation Research Part E, 46, 683-692.

Crawford, P. L. (1960). Hazard exposure differentiation necessary for the identification of the accident-prone employee. Journal of Applied Psychology, 44, 192-194.

Crawford, W. A. (1971). Accident proneness: An unaffordable philosophy. Medical Journal of Australia, 2, 905-909.

Cresswell, W. L., \& Froggatt, P. (1963). The Causation of Bus Driver Accidents: An Epidemiological Study. London: University Press.

Engel, H. O. (1991). Accident proneness and illness proneness: a review. Journal of the Royal Society of Medicine, 84, 163-164.

Daigneault, G., Joly, P., \& Frigon, J.-Y. (2002). Previous convictions or accidents and the risk of subsequent accidents in older drivers. Accident Analysis and Prevention, 34, 257-261.

Department for Transport (2008). Reported Road Casualties 2007: Annual Report. Transport Statistics Publication. London.

Department for Transport (2009). Reported Road Casualties 2008: Annual Report. Transport Statistics Publication. London.

Dorn, L., \& af Wåhlberg, A. E. (2018). Behavioural culpability for traffic accidents. Transportation Research Part F: Traffic Psychology and Behaviour, 60, 505-514. 
Farmer, E., \& Chambers, E. G. (1926). A Psychological Study of Individual Differences in Accident Rates. Industrial Health Research Board Report No 38. London: His Majesty's Stationary Office.

Farmer, E., \& Chambers, E. G. (1929). A Study of Personal Qualities in Accident Proneness and Proficiency. Industrial Health Research Board Report No 55. London: His Majesty's Stationary Office.

Farmer, E. \& Chambers, E. G. (1939). A Study of Accident Proneness Among Motor Drivers. Industrial Health Research Board, Report 84. London: His Majesty's Stationary Office.

Field, A. P., \& Gillett, R. (2010). How to do a meta-analysis. British Journal of Mathematical and Statistical Psychology, 63, 665-694.

French, D. J., West, R. J., Elander, J. \& Wilding, J. M. (1993). Decision-making style, driving style, and self-reported involvement in road traffic accidents. Ergonomics, 36, 627-644.

Froggatt P. \& Smiley J.A. (1964). The concept of accident proneness: a review. British Journal of Industrial Medicine, 21, 1-12.

Gebers, M. A. (2003). An Inventory of California Driver Accident Risk Factors. CAL-DMVRSS-03-204. Sacramento: California Department of Motor Vehicles.

Greenwood, M., \& Woods, H. M. (1919). The Incidence of Industrial Accidents upon Individuals with Specific Reference to Multiple Accidents. Industrial Fatigue Research Board, Report No 4. London: His Majesty's Stationary Office.

Greenwood, M., \& Yule, G. U. (1920). An inquiry into the nature of frequency distributions representative of multiple happenings, with particular reference to the occurrence of multiple attacks of disease or of repeated accidents. Journal of the Royal Statistical Society, 83, 255279.

Haight, F.A. (2001). Accident Proneness: The History of an Idea. UCI-ITS-WP-01-4. Institute of Transportation Studies. Irvine: University of California.

Harrington, D. M. (1972). The young driver follow-up study: An evaluation of the role of human factors in the first four years of driving. Accident Analysis and Prevention, 4, 191-240.

Hauer, E., Persaud, B. N., Smiley, A., \& Duncan, D. (1991). Estimating the accident potential of an Ontario driver. Accident Analysis and Prevention, 23, 133-152.

Häkkinen, S. (1958). Traffic Accidents and Driver Characteristics. Doctoral thesis, Finland's Institute of Technology.

Häkkinen, S. (1979). Traffic accidents and professional driver characteristics: A follow-up study. Accident Analysis and Prevention, 11, 7-18. 
Ker, K., Roberts, I., Collier, T., Beyer, F., Bunn, F., \& Frost, C. (2005). Post-license driver education for the prevention of road traffic crashes: A systematic review of randomized controlled trials. Accident Analysis and Prevention, 37, 305-313.

Kunce, J. T. (1967). Vocational interests and accident proneness. Journal of Applied Psychology, 51, 223-225.

Lonero, L. P. (2008). Trends in driver education and training. American Journal of Preventive Medicine, 35, S316-S323.

Lueck, M. D., \& Murray, D. C. (2011). Predicting Truck Crash Involvement: A 2011 Update. American Transportation Research Institute.

Maritz, J. S. (1950). On the validity of inferences drawn from the fitting of Poisson and negative binomial distribution to observed accident data. Psychological Bulletin, 47, 434-443.

Masten, S. V., \& Peck, R. C. (2004). Problem driver remediation: A meta-analysis of the driver improvement literature. Journal of Safety Research, 35, 403-425.

Mayhew, D. R., \& Simpson, H. M. (2002). The safety value of driver education and training. Injury Prevention, 8(Suppl II), ii3-8.

McKenna, F. P., Duncan, J. \& Brown, I. D. (1986). Cognitive abilities and safety on the road: a re-examination of individual differences in dichotic listening and search for embedded figures. Ergonomics, 29, 649-663.

Miller, T. M., \& Schuster, D. H. (1983). Long-term predictability of driver behaviour. Accident Analysis and Prevention, 15, 11-22.

Miyazaki, A., Chou, M., \& Maruyama, K. (1994). Causal analysis of aptitude, driving behavior, and accidents through the use of covariance structure analysis: Based on performance data. Tohoku Psychologica Folia, 53, 13-20.

Moffie, D. J., \& Alexander, C. (1953). Relationship of preventable to non-preventable accidents in the trucking industry. Bulletin of the Highway Research Board, 73, 32-41.

Newbold, E. (1927). Practical applications of the statistics of repeated events, particularly industrial accidents. Journal of the Royal Statistical Society, 90, 487-547.

Peck, R. C. (2011). Do driver training programs reduce crashes and traffic violations? A critical examination of the literature. IATSS Research, 34, 63-71.

Peck, R. C. \& Kuan, J. A. (1983). A statistical model of individual accident risk prediction using driver record, territory and other biographical factors. Accident Analysis and Prevention, 15, 371-393.

Peck, R. C., McBride, R. S., \& Coppin, R. S. (1971). The distribution and prediction of driver accident frequencies. Accident Analysis and Prevention, 2, 243-299. 
Porter, C. S. (1988). Accident proneness: A review of the concept. In D. J. Oborne (Ed.) International Reviews of Ergonomics: Current Trends in Human Factors Research and Practices, Vol 2, pp. 177-206. London: Taylor \& Francis.

Roberts, I., Kwan, I., \& Cochrane Injuries Group Driver Education Reviewers. (2008). School-based driver education for the prevention of traffic crashes (Review). The Cochrane Library 2008, (1).

Rushton, J. P., Brainerd, C. J., \& Pressley, M. (1983). Behavioral development and construct validity: The principle of aggregation. Psychological Bulletin, 94, 18-38.

Sass, R., \& Crook, G. (1981). Accident proneness: Science or non-science? International Journal of Health Services, 11, 175-190.

Slocombe, C. S., \& Brakeman, E. E. (1930). Psychological tests and accident proneness. British Journal of Psychology, 21, 29-38.

Strathman, J. G., Kimpel, T. J., \& Leistner, P. R. (2007). Evaluation of the Oregon Driver Improvement Program. Urban Studies and Planning Faculty Publications and Presentations. Paper 138.

Vaa, T. (2003). Impairments, Diseases, Age and Their Relative Risks of Accident Involvement: Results from Meta-Analysis. ТØI report 690/2003.

Visser, E., Pijl, Y. J., Stolk, R. P., Neeleman, J., \& Rosmalen, J. G. (2007). Accident proneness, does it exist? A review and meta-analysis. Accident Analysis and Prevention, 39, 556-564.

Webb, W. B., \& Jones, E. R. (1953). Some relations between two statistical approaches to accident proneness. Psychological Bulletin, 50, 133-136.

West, R., Elander, J., \& French, D. (1992). Decision Making, Personality and Driving Style as Correlates of Individual Crash Risk. TRRL Contractor Report 309. Crowthorne: Transport and Road Research Laboratory.

Whitlock, G. H., Clouse, R. J., \& Spencer, W. F. (1963). Predicting accident proneness. Personnel Psychology, 16, 35-44.

af Wåhlberg, A. E. (2004). The stability of driver acceleration behavior, and a replication of its relation to bus accidents. Accident Analysis and Prevention, 36, 83-92.

DOI 10.1016/S0001-4575(02)00130-6

af Wåhlberg, A. E. (2007a). Long term effects of training in economical driving; fuel consumption, accidents, driver acceleration behavior and technical feedback. International Journal of Industrial Ergonomics, 37, 333-343.

af Wåhlberg, A. E. (2007b). Aggregation of driver celeration behavior data: Effects on stability and accident prediction. Safety Science, 45, 487-500. DOI 10.1016/j.ssci.2006.07.008 
af Wåhlberg, A. E. (2009). Driver Behaviour and Accident Research Methodology; Unresolved Problems. Farnham: Ashgate.

af Wåhlberg, A. E. (2011). The accident-exposure association: Self-reported versus recorded collisions. Journal of Safety Research, 42, 143-146.

http://dx.doi.org/10.1016/j.jsr.2011.01.007

af Wåhlberg, A. E. (2018). The effect of driver improvement interventions on crash involvement; has it been under-estimated? Transportation Research Part F: Traffic Psychology and Behaviour, 54, 349-356. doi.org/10.1016/j.trf.2018.02.027

af Wåhlberg, A. E., Barraclough, P., \& Freeman, J. (2015). The Driver Behaviour Questionnaire as accident predictor; a methodological re-meta-analysis. Journal of Safety Research, 55, 185-212.

af Wåhlberg, A. E., Barraclough, P., \& Freeman, J. (2016). Personality versus traffic accidents; meta-analysis of real and method effects. Transportation Research Part F: Traffic Psychology and Behaviour, 44, 90-104. http://dx.doi.org/10.1016/j.trf.2016.10.009

af Wåhlberg, A. E., \& Dorn, L. (2007). Culpable versus non-culpable traffic accidents; what is wrong with this picture? Journal of Safety Research, 38, 453-459.

af Wåhlberg, A. E., \& Dorn, L. (2009). Bus driver accident record; the return of accident proneness. Theoretical Issues in Ergonomics Science, 10, 77-91.

af Wåhlberg, A. E., \& Dorn, L. (2019). Bus driver accident record; stability over time, exposure and culpability. Theoretical Issues in Ergonomics Science, 20, 590-602.

doi: 10.1080/1463922X.2019.1605629 
2020-04-19

\section{Accident proneness of bus drivers; controlling for exposure}

Dorn, Lisa

Taylor and Francis

Dorn L, af Wåhlberg AE. (2020) Accident proneness of bus drivers; controlling for exposure.

Theoretical Issues in Ergonomics Science, Volume 22, Issue 1, 2021, pp. 32-45

https://doi.org/10.1080/1463922X.2020.1749960

Downloaded from Cranfield Library Services E-Repository 